\title{
Comparison of deformations of the large floating-roof tanks with the results of long-term monitoring
}

\author{
Rashid Mangushev ${ }^{1, *}$, and Sergey Sotnikov ${ }^{1}$ \\ ${ }^{1}$ St. Petersburg State University of Architecture and Civil Engineering, St. Petersburg (SPbGASU), \\ Russia
}

\begin{abstract}
The basic requirements for settlement of steel vertical cylindrical tanks are given. The construction of such a foundation is considered and a method for calculating pile ring foundations of largevolume tanks based on the decisions of K.E. Yegorov and A.A. Bartholomei is proposed. The results of monitoring the settlement of a large-volume tank with a floating roof after the completion of hydraulic tests and three years after its operation are presented. The monitoring results are compared with the results of analytical calculations according to the proposed formulas and numerical methods (finite element method FEM) for various software systems.
\end{abstract}

\section{Introduction}

When designing the bases and foundations for large-volume vertical steel cylindrical tanks with a floating roof, special attention is paid to calculations for the second group of ultimate states - for deformations [1]. The risk of significant non-uniform settlements along the perimeter of the tank can lead to the development of unacceptable stresses in the welded joints of the wall and the bottom, to the appearance of a roll and jamming of the floating roof structure.

As studies [2, 3] showed, the highest stresses and deformations occur in the region of the reservoir junction at a distance of 3-4 m from the wall of large-volume tanks $(\mathrm{V} \geq 10$ thousand $\mathrm{m}^{3}$ ). In order to ensure the normal functioning of the constructions of vertical steel cylindrical tanks during operation, it is necessary at the design stage to correctly evaluate the amount of settlement of various points of the bottom and wall, as well as the degree of unevenness of these movements.

Widely used in practice, the foundations of steel tanks are ring or round slabs supported by sand and gravel pads or piles. Numerous experimental studies show that the device under the tank wall of a monolithic reinforced concrete ring can reduce the unevenness of settlement around the tank perimeter. The use of a ring pile holder in conditions of weak soils, which prevents the soil escaping from the bottom of the tank and restricts horizontal movement of the soil, also reduces the average settlement of the base $[3,4,5]$.

\footnotetext{
*Corresponding author: ramangushev@yandex.ru
} 


\section{Methods}

Calculation of tank base settlement is recommended to be performed by the method of summation based on the solutions of the axisymmetric problem of the elasticity theory obtained by K.E. Egorov [6] to determine the vertical components of the stresses $\sigma_{z}$ and displacements $w$ for the foundations of circular and ring shapes, presented in the following form:

- for a round foundation with radius $R$ (see Fig. 1);

$$
\sigma_{z}=p \alpha(m, t)
$$

where $\alpha$ is the function of elliptic integrals depending on the relations $m=\frac{z}{R}, t=\frac{r}{R}$, 2);

- for a ring foundation with internal and external radii, respectively, $R_{1}$ and $R_{2}$ (see Fig.

$$
\left.\begin{array}{l}
\sigma_{z}=p\left[\alpha_{2}\left(m_{2}, t_{2}\right)-\alpha_{1}\left(m_{1}, t_{1}\right)\right]=p L ; \\
w=\frac{2\left(1-v^{2}\right)}{E} R p\left[\beta_{2}\left(m_{2}, t_{2}\right)-\beta_{1}\left(m_{1}, t_{1}\right)\right],
\end{array}\right\}
$$

where $\alpha(m, t)$ and $\beta(m, t)$ are functions expressed in terms of elliptic integrals depending on the corresponding radii of the ring $R_{1}<R_{2}$ and variables

$$
m_{1}=\frac{z}{R_{1}}, m_{2}=\frac{z}{R_{2}}, t_{1}=\frac{r}{R_{1}}, t_{2}=\frac{r}{R_{2}} \text {. }
$$

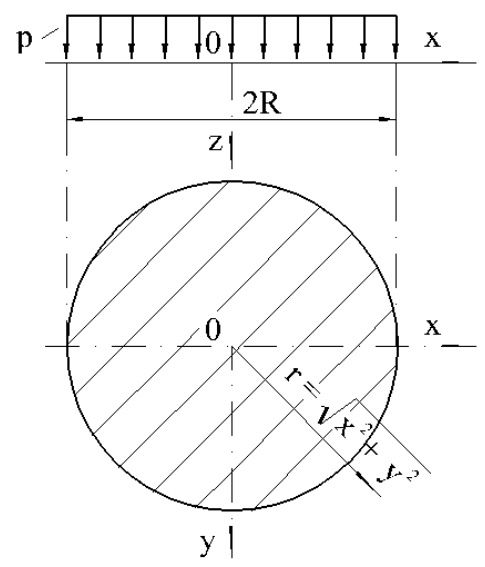


Fig. 1. Scheme for the determination of settlements of a round foundation, loaded with a uniformly distributed load.

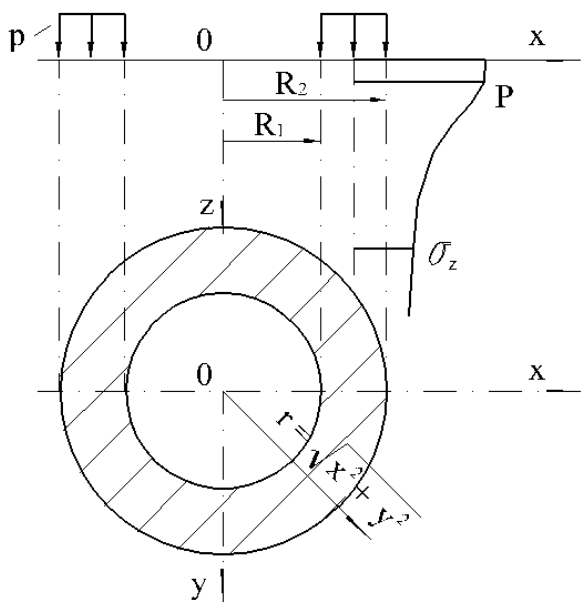

Fig. 2. Scheme for determining the settlement of a ring foundation loaded with a uniformly distributed load.

\section{Results and discussion}

Based on the available solutions, a computer program algorithm was developed for a PC for calculating the ring pile foundation settlements, which takes into account the well-known methods for determining stresses in the active zone and methods for calculating the total settlements of strip pile foundations, taking into account the application of the load inside the solid and the type of diagrams of its transfer along the lateral surface and in planes of the pile edge based on the analytical solution of A.A. Bartolomei [7].

The need to develop this software tool arose when designing the foundations of two steel cylindrical tanks with a capacity of 50 thousand $\mathrm{m}^{3}$ (tank diameter $-60.7 \mathrm{~m}$, height $18.0 \mathrm{~m}$ ) with a floating roof for storing oil products in the territory of an oil refinery in the Leningrad Region. The tank construction site was located on the territory previously occupied by former artificial ponds for sedimentation of contaminated water and subsequently covered with bulk soil. Specially performed additional engineering and geological surveys revealed the presence of lenses of weak soil under the spots of tank construction.

Preliminary calculations made it possible to recommend the foundation-filling under the bottom and the ring pile foundation with a monolithic reinforced concrete strip grillage under the walls of the tanks as the foundations for the tanks (see Fig. 3). 


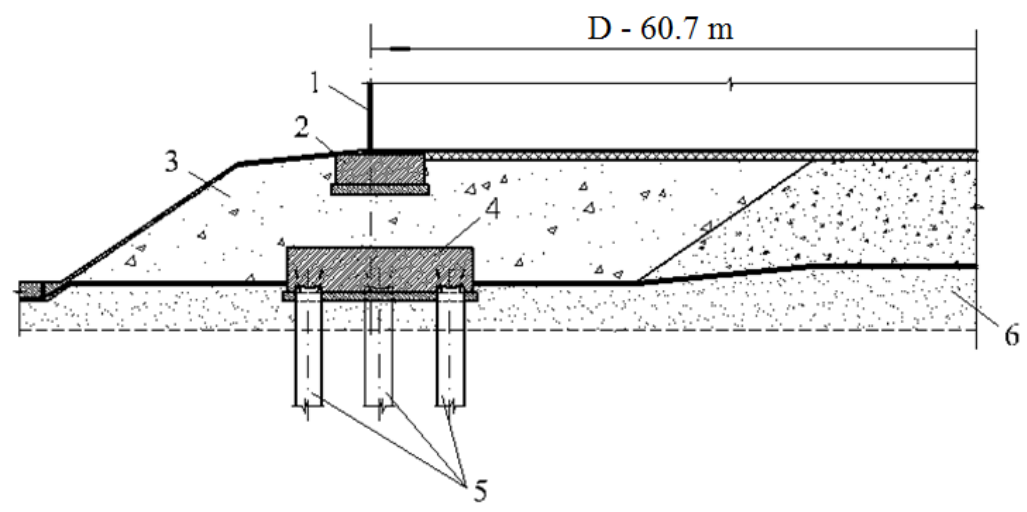

Fig. 3. The design of the ring pile foundation for the tank, in the base of which was found a lens of weak soil: 1 - the wall of the tank, 2 - ring monolithic reinforced concrete foundation on concrete preparation, 3 - intermediate crushed stone pad, 4 - monolithic grillage, 5 - piles, 6 - sand pad under the bottom of the tank.

After the construction of the tanks, their hydraulic tests were carried out, during which regular geodetic observations of tank settlements were established. Geodetic observations were carried out according to a specially developed program. To measure the deformations of the tank bases, four highly stable initial reference points were installed on the territory of the tank farm. During geodetic observations, leveling of metal grades from a corner was carried out, which were welded to the walls of the tanks at a distance of $6 \mathrm{~m}$ around the perimeter and ensured accurate reading. According to the technological map for conducting hydraulic tests of tanks, tanks were filled with water in steps of $2.5 \mathrm{~m} ; 6.0 \mathrm{~m} ; 11.0 \mathrm{~m}$ and $17.4 \mathrm{~m}$. After each loading stage, the elevations of the grades and the increment of deformations were determined. Based on the data obtained, the settlement diagrams of the tank wall were constructed at different load values and graphs of the settlement development (average, maximum and minimum) in time taking into account the load of the base (see Fig. 4). 
a)

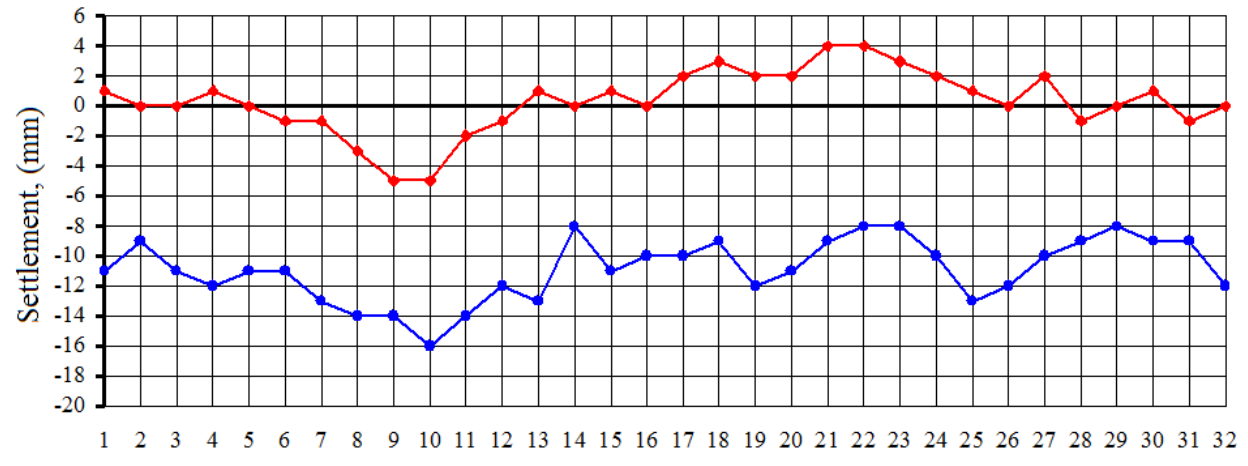

No grade

$\rightarrow$ full load $\quad \rightarrow$ after discharge

b)

$\mathrm{H}, \mathrm{m}$

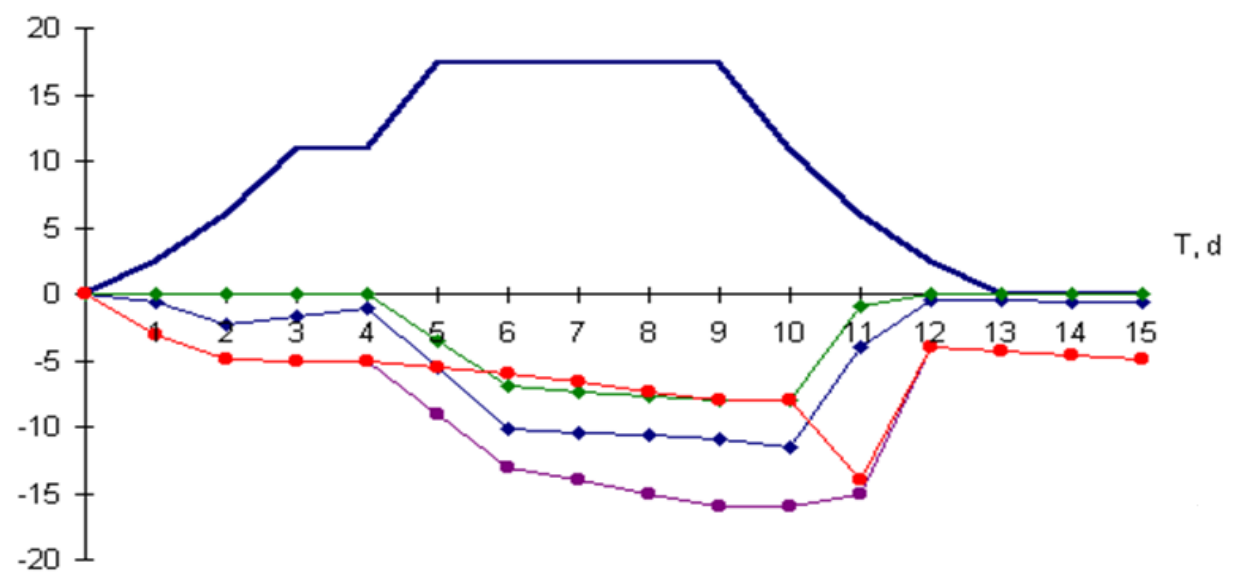

$\mathrm{S}, \mathrm{mm}$

$\mathrm{H}, \mathrm{m} \longrightarrow \Delta \mathrm{Sav} \rightarrow \Delta \mathrm{Smax} \longrightarrow \Delta \mathrm{Smin} \longrightarrow \Delta \mathrm{S}$

Fig. 4. a) Diagrams of the tank wall settlement at different values of the load. b) Graphs of the settlement development in time for the tank, at the base of which there is a lens of weak soil.

The measured values of the tank settlements immediately after the hydraulic tests and three years after the start of operation are compared with the calculated values obtained in the analytical solution of the axisymmetric problem, the planar problem of elasticity theory using the FEM using the Geomechanics program developed in LISI [6] and using the software package PLAXIS.

Based on the performed calculations, graphs of the dependence of the ring pile foundation settlement calculated by various methods on various load levels in comparison with those observed at the time of completion of the hydraulic tests and three years after the start of their operation were constructed (Fig. 5). 


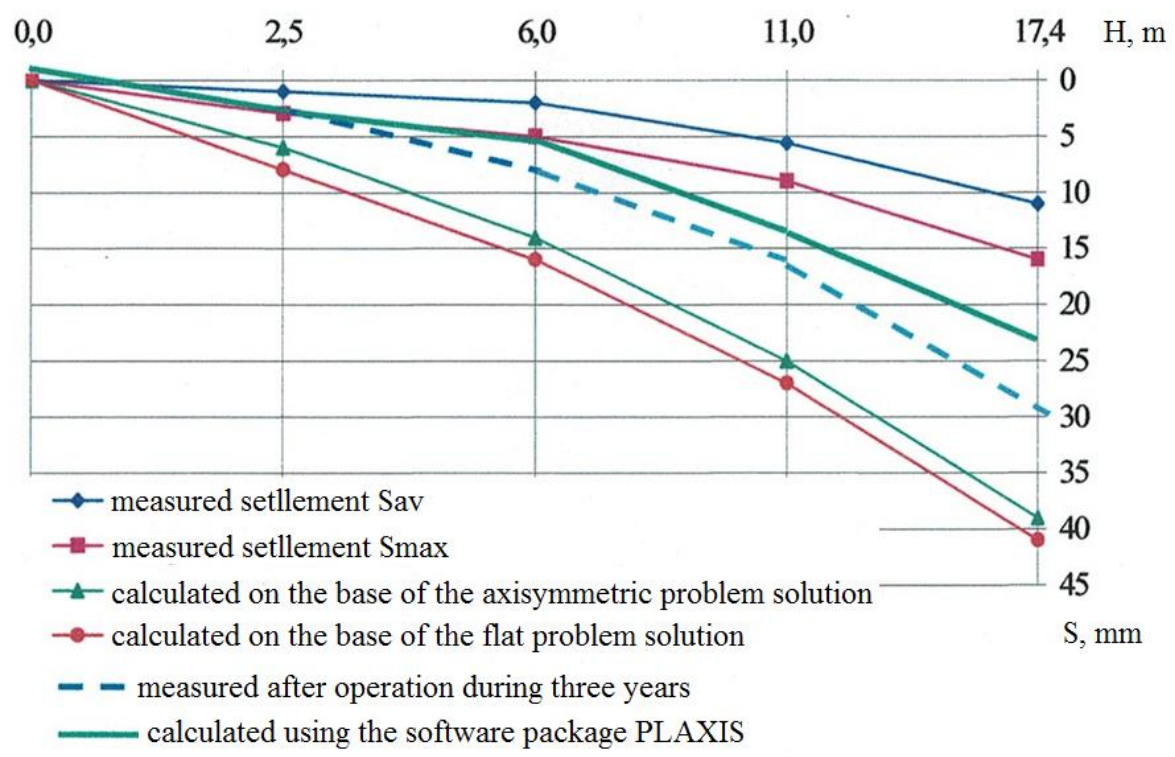

Fig. 5. Graphs of the settlement dependence on the load for the tank at the base of which is located the lens of weak soil.

From the presented graphs it follows that the calculated values of settlements are 2-3 times higher than the measured values at the time of completion of the hydraulic test. In the future, over 3 years, their growth has been observed. In this case, the calculations by the finite element (FEM) program PLAXIS most fully reflect the values of the measured settlement tanks.

\section{Conclusions}

1. The developed analytical method for calculating tank settlement calculation method allows performing an overestimation of the final tank settlement after several years of operation.

2. The method of calculating the final settlement (after three years) using the PLAXIS program in a flat setting is more accurate.

\section{References}

1. SP. 22.13330. Foundations of buildings and structures, Moscow (2016)

2. S.N. Sotnikov, R.A. Mangushev, Review inf. Ser. "Oilfield construction", VNIIOENG, Moscow (1981)

3. P.A. Konovalov, R.A. Mangushev, S.N. Sotnikov, et al., The foundations of steel tanks and the deformation of their bases (monograph), 336, ASV Publishing House, Moscow (2009)

4. S.N. Sotnikov, R.A. Mangushev, I.V. Ganushchenko, Express inf. Ser. "Oilfield Construction", 9, VNIIOENG, Moscow (1984)

5. Yu.K. Ivanov, P.A. Konovalov, et al., The bases and foundations of tanks (Stroyizdat, Moscow, 1989)

6. K.E. Egorov, To the calculation of base deformations, GUP "VNIINTPI", Moscow (2002) 
7. A.A. Bartolomei, Basics of calculating strip pile foundations for maximum permissible settlement (Stroyizdat, Moscow, 1982)

8. FA.B. Fadeev, The finite element method in geomechanics (221, Nedra, Moscow, 1987)

9. Handbook of geotechnics. Bases, foundations and underground structures (1040, 2nd ed., under the general eds. of V.A. Ilyichev and R.A. Mangushev, ASV Publishing House, 2016)

10. M.P. Balaam, Proceedings of the 5-th Southeast Asian Conference on Soil Engineering, 81-90 (1977)

11. R.A. Bell, J. Iwakiri, Proc. ASCE, 106, No GT2, 153-169 (1980)

12. L. Belloni, A. Garassino, M. Jamilkowski, Proceedings of the Conference on Settlement of Structures, 323-328, Pentech Press, London (1975)

13. D.A. Greenwood, Conference on settlement of structures, Pentech Press, London (1975)

14. Y.S. Kim, C.K. Shen, S. Bang, 8-th ECSMFE, 1, 371-374, Helsinki (1983)

15. R. Rosenberg, N.L. Journeaux, Canadian geotechnical j., 19, No. 3, 232-238 (1982)

16. R.A. Sullivan, J.F. Nowickl, Proceedings of the Conference on Settlement of Structures, Pentech Press, London, 420-424 (1975) 